\title{
Research and Practice of Data Structure Curriculum Reform Based on Outcome-Based Education and Chaoxing Platform
}

\author{
Dongqing Wu, Pengfei Guo, Chaolong Zhang, Chaojun Hou, Qian Wang, and Zhiwei Yang
}

\begin{abstract}
In view of the problem of the data structure course being difficult to learn and teach, this paper analyses the characteristics and pain points of the course. We implement the concept of 'student-centered' education, combine outcome-based education and heuristic teaching, take students' learning effect as guidance and construct the curriculum according to the requirement of the industry. Combining students' autonomous learning, teachers' blackboard writing and on-site programming, we practice the educational concept of students as the main body and teachers as the auxiliary part. Finally, we highlight the significance and prospects of the results of this research and conclude that the research results are effective.
\end{abstract}

Index Terms-Curriculum teaching reform, OBE, heuristic teaching, data structure.

\section{BACKGROUND}

Data structure is a way for computer to store and organize data; it contains a series of algorithms closely related to the structure [1], [2]. Data structure is the core professional basic course of information and computing science, and it is an important theoretical and practical basis for system development. This course discusses the implementation of logical structure, storage structure, operation of typical data structures and design methods of algorithms [3].

The knowledge content and technical methods of data structure course are necessary for computer professionals. It is not only an important basic course for other courses in the computer field but also necessary for the development of large-scale information engineering. In view of the importance of curriculum, the research on curriculum reform has always been a hotspot for educators at home and abroad. The course has distinct characteristics, making it difficult to teach and learn.

\section{PROBLEMS}

Our college has started the research in the course reformation of data structure since 2016, and good research results have been achieved. Specific analysis has the following four aspects.

Manuscript received January 1, 2021; revised February 2, 2021.

The authors are with College of Computational Science, Zhongkai University of Agriculture and Engineering, Guangzhou 510225, China (e-mail: dongqing.wu@hotmail.com).

\section{A. Highly Theoretical Content and Its Problems}

The logic structures and algorithms discussed in this course involve a large number of concepts, structures and algorithms with profound connotation and are highly interrelated. At the same time, these contents are extracted and abstracted from a large number of programming practices and are strictly described by mathematical formal language. Moreover, the course content itself is not limited to a specific programming language; therefore, it is considered to be more theoretical than the general programming courses.

In the traditional data structure course teaching, the course content is too rigorous; that is, the logical structure of the data is often represented by abstract data types, and the abstract data types are more formally described by mathematical symbols, making the abstract data structure and algorithm more difficult to understand. At the same time, the algorithm in mainstream textbooks is described by pseudocode, which is common in academic papers. In addition, a large section of implementation code is often given at one time, making the learning curve too steep, and it is very difficult for students to understand.

\section{B. Comprehensive Curriculum and Its Problems}

First of all, the logic structure, storage structure and algorithm discussed in the course of data structure depend on the relevant theory of discrete mathematics and the programming knowledge and skills in programming. Secondly, this course is also an important foundation for subsequent important courses. Moreover, the contents of each chapter are closely linked. In addition, the course is the core content of postgraduate entrance examination for it majors. Therefore, the course served as a bridge between the past and the future in the whole process of professional education.

Meanwhile, this course algorithm often needs to use class, reference, loop control structure, and other knowledge points, but students generally have the same problem: in freshmen who have learned programming, the forgetting ratio of syntax is high, and the ability of students to debug is insufficient. In addition, the data structure that has not learned the accumulated disadvantages will also drag down the learning effect of the follow-up course. Because the derivation and construction process of data structure and algorithm is quite abstract and strict, and the knowledge points are closely linked, it is difficult for students to keep up with the learning progress if they lack necessary foundation of relevant knowledge and skills.

\section{Intensive Practicality of Curriculum and Its Problems}


From the teaching practice of peers at home and abroad, it is concluded that understanding a specific data structure is totally different from programming to realize the complete functions and algorithms of the data structure. The implementation of simplified API for some basic data structures can greatly improve the understanding of the internal details of data structures.

However, the students generally have the problem of poor practical ability. Even if students understand in class, programming is still an insurmountable obstacle. The programming practice of students is insufficient, and this leads to insufficient intuitive understanding of the structure between the data. Students do not know where to start when debugging. They undergo a high sense of frustration, which affects their confidence. As time goes by, they lose interest in learning the course. The reason for this problem is the fact that the old curriculum assessment does not evaluate practical ability, and this misleads some students to neglect practicing.

\section{The Strong Interactivity of Curriculum Learning Needs and Its Problems}

The course content itself is quite difficult. In addition to comprehensive and moderately difficult teaching materials and teaching videos that can be watched any time, students also need to interact with teachers and potential helpers in all aspects of learning (before, during and after class).

However, the common scene in the teaching of 'data structure' is that teachers use slides presentation according to their own pace. Algorithm principle or code is presented in slide shows at one time, and pages are turned before the students can understand and digest information, leading to students' disorientation in the process of listening. In addition, large classes are inevitable, and the teacher's energy is limited; therefore, the manual summary and analysis of learning situation are undoubtedly very difficult. Thus, the accurate analysis of learning situation is critical to improve the quality of teaching.

To summarise, the course is really challenging for both teacher and students. In view of the crucial position of data structure in the training of professional talents, authors established a course team in 2016 to actively innovate and practice and carry out the course teaching reform using information technology.

\section{RELATED THEORIES}

In this section, three teaching theories related to this research will be introduced.

\section{A. Outcome-Based Education}

With the popularity of network teaching and outcome-based education (OBE) teaching [4], [5], researches on curriculum reform are increasing. The implementation framework of OBE can be summarised as follows: one core objective, two important conditions, five connotations, four implementation principles and five implementation points [4], [5]. In short, OBE requires students to show their ability to think, question, research, decide and present through challenging tasks. Therefore, OBE aims to place students in a well-designed environment to develop their ability. OBE pays more attention to high-level abilities, such as creative thinking, analysing and synthesising information and planning and organisation. These abilities can be obtained by completing some complex tasks by team.

\section{B. Student-Centred Teaching}

'Student-centred' is the basic idea of modern education and the extension of subjective education [6], [7]. Its theoretical basis is humanism and constructivism. Amongst them, the core starting point of humanism is to emphasise the differences of individual starting points, that is, the diversity of starting points. Constructivism, on the other hand, emphasises the diversity of learners' cognitive structure. There are seven principles of learner-centred teaching:

1) Teachers should do less, and students should do more.

2) Teachers should try their best to 'inform' students less and give them more opportunities to 'discover'.

3) Teachers should design as many tasks as possible around the teaching objectives.

4) Teachers should prepare as many models as possible to help students learn.

5) Teachers should try to encourage students to learn from each other.

6) Teachers should strive to create an atmosphere and environment that are conducive to learning.

7) Teachers should provide rich feedback information, including formative and summative assessment and comments.

In short, one should focus on students rather than teachers.

\section{Heuristic Teaching}

Heuristic teaching is a teaching method that implements the idea of 'student-centred' teaching [8]. It emphasises that teachers should guide students rather than lead them to go, so that the relationship between teachers and students will be harmonious; encourage students rather than suppress them, so that students can obtain a pleasant experience from learning; and instruct students without providing ready-made answers, so that students can enter a state of positive thinking [9]. There are four common enlightening points. First, the teacher chooses the enlightening point on the connection point of knowledge. Second, the teacher finds inspiration in the key points of new knowledge. Third, the teacher looks for heuristic points in the 'stuck' part of the answer. Fourth, the teacher explores the inspiration from the mistakes in practice.

The above education and teaching theories provide valuable inspiration for improving the teaching quality of data structure course.

\section{INNOVATIVE IDEAS TO IMPROVE THE QUALITY OF TEACHING}

In view of the existing problems and learning situation of the course, our team has conducted continuous teaching reform in recent years, actively implemented the concept of 'student-centered' education, combined OBE and heuristic teaching, guided students' learning effect and fully reflected the education concept of combining students' autonomous learning with teachers' teaching, that is, student-centered and teacher-assisted. Specific ideas are as follows. 


\section{A. Set a Reasonable Teaching Objective to Solve the Problem Caused by the Highly Theoretical Course}

This activity is mainly based on the idea of being 'student-centered'. Although most of the course teachers are $\mathrm{PhD}$ of computer science and have extensive knowledge. However, they generally lack the theory and skill training of pedagogy. Therefore, setting teaching objectives according to teachers' own knowledge ability and accomplishment is easy; however, this is contrary to the student-centered teaching idea. Therefore, reform is needed. The objective and framework of the teaching content should be designed based on knowledge map architecture. In the framework of the overall objectives of the course, the overall learning objectives are established. On the basis of the knowledge map of software engineers organized by the previous professional quality engineering projects, combined with the students' level and acceptance ability, the knowledge map architecture is used to design and create a knowledge map convenient for students to clarify the content system of data structure. The consistency and correctness of the knowledge map is repeatedly tested to ensure the quality of knowledge mapping.

\section{B. Choose Suitable Teaching Materials and Methods to Solve the Problems Caused by the Comprehensive Curriculum}

This activity is mainly based on the idea of OBE. In this paper, the OBE theory is applied to the course of data structure. Firstly, the appropriate prerequisite and follow-up courses that can fully reflect the continuity of knowledge are determined. Especially for students majoring in information and computing science, laying a solid foundation of data structure programming in the introductory programming course of freshman is the core problem. Traditionally, data structure ( $\mathrm{C}$ language version) by Yan Weimin of Tsinghua University has been adopted in the course of data structure in most colleges and universities, partly because most teachers study this book. This book has a high requirement for $\mathrm{C}$ language. $\mathrm{C}$ language has many advantages; however, it is unsuitable for this course because $\mathrm{C}$ language has relatively difficult language features (such as pointer) and less valued exception handling mechanism [10]. Therefore, we choose Java as the description language because it is easy to get started. In terms of teaching methods, the reform was based on the standard of gender, and it pays attention to the integration of knowledge, ability, quality and cultivates students' comprehensive ability to solve complex problems. In terms of curriculum content, it stresses the reflection of the frontier and times. The teaching form is advanced and interactive, and the learning results are exploratory and personalised

\section{A Large Number of Heuristic and Problem-Based Teaching}

This teaching reform activity is mainly based on heuristic teaching. In view of the intensive practicality of the course, simply turning slides and reading textbooks in class cannot explain the theory. In the class, examples that are known well by the students should be used, and based on it, new algorithms or data structures are introduced. Furhermore, situational conflicts should be created. Thus, students' desire for knowledge is therefore stimulated. In the ways, algorithms and data structures are gradually constructed using real programming from scratch to show students how a complex algorithm is constructed from imperfect to perfect process. Knowledge points are presented from abstract (concept) to concrete (daily life instance) and then to abstract (program language description).

\section{Make Full Use of the Chaoxing Learning Platform to} Solve the Problems of Strong Interaction

To actively implement the OBE teaching idea, we make full use of the convenience and quickness of the Chaoxing learning platform. The platform comprehensively adopts the means of autonomous learning, centralized teaching of difficult points and group discussion before and after class experiments; it also guides students to participate in extracurricular innovative practices [11], [12]. Therefore, it is suitable to achieve the OBE results of reasonable, orderly and progressive teaching [13], [14]. With the help of the Chaoxing learning platform and task-driven method, we can carefully prepare self-study videos before class, arrange open thinking before class, test in class and feedback after class, as well as help teachers check mistakes, to encourage students to internalize knowledge and summaries feedback.

\section{MEASURES, EFFECTS AND REFLECTIONS ON IMPROVING THE QUALITY OF CURRICULUM TEACHING}

According to the characteristics of the data structure course and the specialty of information and computing science, the course team designed a student-centred OBE teaching mode based on Chaoxing as shown in Fig. 1.

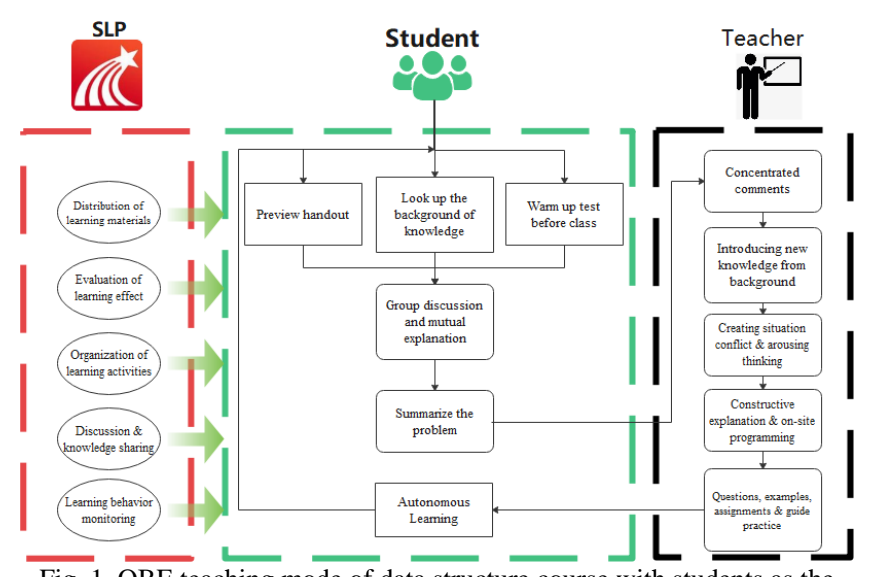

Fig. 1. OBE teaching mode of data structure course with students as the centre.

The specific measures of this teaching mode are as follows:

A. The Three Stages of Pre-class, in-Class and after-Class are Closely Linked to Increase Students' Participation in Learning

In the pre-class stage, the teacher arranges preview handouts on the Chaoxing platform in advance to let the students complete the warming-up test. Then, students are urged to independently check the background and historical development of the knowledge points and are encouraged to 
discuss in groups. In the class, the teacher focuses on the students' problems and test results and introduces new algorithms or data structures from the familiar examples or algorithms. First, the teacher creates situational conflict and stimulates students' desire for knowledge. Second, the teacher gradually constructs algorithms and data structures using real programming from scratch to show students how a complex algorithm is constructed from imperfect to perfect process. The whole process presents the knowledge point from abstract (concept) to specific (life examples) and then to abstract (program language description) transformation, with a large number of questions, examples and classroom practice. Thus, it will effectively help students internalize the knowledge to be learned. After class, the teacher timely uploads the class video and course summary to Chaoxing platform and assigns tasks. The students ruminate and independently learn based on the teaching resources published in Chaoxing. They can also use group discussion or the Internet to ask the teacher problems. Through these ways, they consolidate their knowledge through exercises after class and computer practice.

\section{B. Organise Interesting Games to Deepen the Understanding of Abstract Theory}

Taking the problem of how to avoid misreading of Huffman compression coding, an application of binary tree, as an example, after the students have mastered the basic algorithm of binary tree, four students are selected to play the roles of 'Niulang' and 'Zhinu' in the scene of dialogue across the galaxy, which is excerpt of the story of Chinese Valentine's Day. Two students play the role of 'Niulang' and encode a sentence according to the binary code table; they then send signals to the 'Zhinu' group and the students at the scene through gestures ( 0 or 1$)$. The 'Zhinu' and the other students at the scene record the gestures of 'Niulang' in turn and translate them according to the binary code table. Through this game, in the participation of students and relaxed atmosphere, all the students feel that the boring and repulsive algorithm becomes interesting, and they also experience the process of signal coding, transmission and decoding, providing them with intuitive understanding of the compression algorithm.

\section{Use Blackboard-Driven, Step-by-Step Method to Explain the Algorithm and Demonstrate Programming Teaching Methods}

The process of understanding and implementing the algorithm is the process of abstracting and summarizing the specific operation steps. In the algorithm, if the presentation method is improper, such as 'three more' (more condition judgement, more variables, and more nested loops), many students are often deterred. At this time, teachers can take a step-by-step design method by, first, clearly describing the process of the algorithm in word; second, using the top-down design method one by one correspondingly and, lastly, dividing the programme into blocks according to the function to reduce the difficulty of understanding. Taking the partition algorithm in quick sort as an example, we 'translates' the algorithm into program statements described by the text step by step, with notes and appropriate blank-leaving. In this way, the students can fill in the blanks and write the partition algorithm and the calling statements in the main method. In the first version of the algorithm, using too many variables and loops is not suitable as this may bring unnecessary confusion. After the algorithm is initially complete, the constant is replaced by variables one by one, and the sequence structure is replaced by the loop structure. The final version of the algorithm is obtained through continuous iteration. In this way, we can help students construct knowledge system in a step-by-step manner.

\section{Combine the Course Content with Familiar Examples}

Familiarity can result in understanding. When students feel that the new knowledge is 'useful' and familiar, they will be interested and confident to learn. Taking Dijkstra single-source shortest path algorithm as an example, students can provide campus shortest path query service for freshmen. Another example is the new coronavirus gene sequencing problem from the National GeneBank (https://db.cngb.org/virus/ncov). We guided the students to download the real COVID-19 gene sequence and use Knuth-Morris-Pratt string search algorithm to solve this problem. By analyzing these familiar and interesting examples, students are more motivated and confident to learn how to abstract data structures, design and apply algorithms to solve problems and try to transfer the learned knowledge to cultivate their application ability.

\section{E. Actively Implement the Strategy of Promoting Training and Learning by Competition}

The ACM International Collegiate Programming Contest (ACM/ICPC) and Blue Bridge Cup programming competition are the most valuable 'Olympic' competitions in the programming field of college students [15]. This course takes the real problem on the platform of ACM program competition of Peking University as the evaluation standard to carry out the teaching practice of achievement-driven algorithm and data structure course. The students are encouraged to solve problems by reading the corresponding chapters. In addition, we also actively implement 'promoting learning by competition', and select a group of students to participate in the ACM/ICPC and Blue Bridge Cup programming competition every year. This real problem-driven teaching mode enables students to compete with domestic and foreign programming experts at the same time, effectively mobilising students' learning enthusiasm.

\section{F. Actively Carry out Heuristic Teaching}

This is a kind of teaching method to guide students to solve problems and improve students' learning interest and initiative by setting appropriate problems in teaching. The first type of data structure in general textbook research is array structure. If students can deeply understand this part, it will be of great help to their future learning. It is helpful for students to take part in this part of learning and enhance their self-confidence. When the students have discussed the feasible steps of inserting new elements into the array structure, the students will be asked to answer the key statements of the insertion algorithm. These key statements are given by the students themselves, and these sentences not only deepen their impressions but also their understanding of 
the algorithm.

\section{G. Help Students Carrying out Class Reflection Based on Chaoxing Platform}

Students can repeatedly watch the videos of the learning platform, and the key knowledge documents given by teachers can help students internalise and acquire new knowledge. In the test phase, teachers rely on the Chaoxing platform, according to the data collected before the students' learning, personalise the test phase, set the test from simple to difficult and provide different difficulty test questions and experimental tasks for different students to more comprehensively diagnose the students' mastery of knowledge and provide data support for teaching diagnosis.

\section{EMPIRICAL STUDY OF TEACHING EFFECT}

We set up two teaching classes (70 students) of data structure in grade 2016 as the experimental group (EG) and implemented the one-semester teaching reform. To compare the effect of teaching reform, we chose another two classes (68 students) as the control group (CG). We obtained the statistical data of students' learning behavior on Chaoxing platform, including login times, material download times, video viewing time, questioning times, correct answer rate and team cooperation times. We then quantified the learning effect through questionnaire survey. Next, we analyzed the data, and the results are shown in Table I.

TABLE I: COMPARISON OF LEARNING OUTCOME SCORE BETWEEN THE EXPERIMENTAL AND CONTROL GROUPS

\begin{tabular}{|c|c|c|c|c|c|c|c|c|c|c|}
\hline \multirow{2}{*}{$\begin{array}{r}\text { EI } \\
\text { Group }\end{array}$} & \multicolumn{2}{|c|}{$\begin{array}{c}\text { Knowledge } \\
\text { understanding } \\
(25 \text { pts })\end{array}$} & \multicolumn{2}{|c|}{$\begin{array}{c}\text { Analytical ability } \\
\text { (25 pts) }\end{array}$} & \multicolumn{2}{|c|}{$\begin{array}{c}\text { Practical ability } \\
\text { (30 pts) }\end{array}$} & \multicolumn{2}{|c|}{$\begin{array}{c}\text { Innovation } \\
(20 \text { pts })\end{array}$} & \multicolumn{2}{|c|}{$\begin{array}{c}\text { Total } \\
(100 \text { pts })\end{array}$} \\
\hline & $\mathrm{CG}$ & EG & $\overline{C G}$ & EG & $\mathrm{CG}$ & EG & $\mathrm{CG}$ & EG & $\mathrm{CG}$ & EG \\
\hline Max./Min. & $23.1 / 10.0$ & $24.8 / 12.3$ & $22.4 / 11.2$ & 23.1/15.9 & $27.0 / 16.8$ & $29.0 / 20.2$ & $15.7 / 8.5$ & 19.3/10.2 & $86 / 40$ & $95 / 61$ \\
\hline Avg. & 16.2 & 18.5 & 14.3 & 19.4 & 20.1 & 24.3 & 12.8 & 14.4 & 62.3 & 77.8 \\
\hline SD & \pm 4.5 & \pm 2.9 & \pm 4.9 & \pm 3.7 & \pm 3.2 & \pm 1.9 & \pm 4.5 & \pm 4.1 & \pm 23.9 & \pm 15.0 \\
\hline
\end{tabular}

Note: 'EI' represents 'evaluating indicator', 'Max./Min.' represents 'maximum/minimum', 'Avg.' represents 'average', and 'SD' represents 'standard deviation'.

It can be seen from the table that the average scores and total scores of the four curriculum objectives of the EG are significantly better than those of the CG. Furthermore, the standard deviations of the EG are also lower than its counterpart, indicating that the polarisation phenomenon is also significantly improved. Therefore, it further substantiates that the curriculum reform measures have achieved the expected learning outcomes.

\section{RESUlts OF PROBLEM-SOLVING}

\section{A. Quality Improvement of Personnel Training}

In the recent three years, students have won 52 awards above the provincial level in the programming competitions: Blue Bridge Cup software design competition, National College Students' mathematical modelling competition, National College Students' statistical modelling competition, 'Teddy Cup' data mining competition, Oracle Software Innovation Competition, etc. The improvement of programming ability has also further promoted the quality of students. In the recent two years, the average initial employment salary of graduates significantly increased. In terms of professional attraction, the first voluntary enrolment rate is more than $100 \%$. The effect of talent training is remarkable.

\section{B. Feedback Effect of Students}

On the one hand, the results of ability evaluation and questionnaire statistics after the end of 2016-2019 show that the degree of achievement of teaching objectives set by the course has increased by $30 \%-40 \%$ compared with that before the reform. On the other hand, the teaching evaluation scores of the lecturers have increased to $90.69 \%, 93.31 \%$, and 94.62 , respectively, from 2016 to 2019 . In addition, it also reflected the mutual benefit of teaching and learning. Team teachers have won three first prizes and two second prizes of the school's excellent teaching quality award. Two teachers won the honorary title of 'My Favorite Teacher' of students in our university.

\section{Popularisation and Application of Achievements}

In the past three years, members of the course team have won three university-level teaching achievement awards and published eight related papers. As the only case recommended by our university, the achievements of curriculum reformation were selected into the case collection of applied undergraduate talents training reform achievements in Guangdong Province, China. The achievements of the curriculum innovation have been highly recognized by counterparts in many other universities.

\section{CONCLUSION}

By analyzing the characteristics and pain points of data structure course teaching, we conducted the teaching reform based on Chaoxing platform and OBE idea. The teaching reform program has been proved to be effective in practice. Therefore, one can learn from the teaching mode, teaching methods and evaluation methods of this innovation to improve the teaching effect. Similarly, for the related curriculum reform of the same level of undergraduate colleges, we can also learn from this innovation.

\section{CONFLICT OF INTEREST}

The authors declare no conflict of interest.

\section{AUTHOR CONTRIBUTIONS}

Dongqing $\mathrm{Wu}$ conducted the research and wrote the paper; 
Pengfei Guo and Chaolong Zhang analyzed the data; Chaojun Hou provided valuable experimental data. Qian Wang and Zhiwei Yang participated in valuable modification suggestions for the paper.

\section{REFERENCES}

[1] M. T. Goodrich, R. Tamassia, and M. H. Goldwasser, Data Structures and Algorithms in Java, Hoboken, New Jersey: John Wiley \& Sons, 2014, ch. 1.

[2] C. A. Shaffer, A Practical Introduction to Data Structures and Algorithm Analysis, Upper Saddle River, New Jersey: Prentice Hall, 1997, ch. 2.

[3] S. I. Ahamed, "Experiences in teaching an object-oriented design and data structure course," in Proc. ITCC 2003. International Conference on Information Technology: Coding and Computing, Las Vegas, NV, USA, 2003, pp. 48-52.

[4] J. Mohanta and S. K. D. Mandal, "The effectiveness of the outcome-based curriculum towards improving educational quality for technical education," in Proc. 2019 IEEE Tenth International Conference on Technology for Education (T4E), Goa, India, 2019, pp. 242-243.

[5] K. M. Evans and J. A. King, "Research on OBE: What we know and don't know," Educational Leadership, vol. 51, no. 6, pp. 12-17, Mar. 1994.

[6] A. B. Hunter, S. L. Laursen, and E. Seymour, "Becoming a scientist: The role of undergraduate research in students' cognitive, personal, and professional development," Science Education, vol. 91, no. 1, pp. 36-74, Jan. 2010.

[7] L. Cuban, How Teachers Taught: Constancy and Change in American Classrooms, 1890-1990, Research on Teaching Series, 2rd ed. New York, NY: Teachers College Press, 1992.

[8] C. J. Ury, C. V. Johnson, and J. A. Meldrem, "Teaching a heuristic approach to information retrieval," Research Strategies, vol. 15, no. 1, pp.39-47, Jan. 1997,

[9] K. Reiss and A. Renkl, "Learning to prove: The idea of heuristic examples," Zentralblatt für Didaktik der Mathematik, vol. 34, no. 1, pp 29-35, Jan. 2002

[10] C. A. Shaffer, A Practical Introduction to Data Structures and Algorithm Analysis, Upper Saddle River, New Jersey: Prentice Hall, 1997, ch. 1.

[11] X. Feng and M. Wang, "Exploration on blended teaching reform based on mobile learning platform (ChaoXing) - Take English linguistics as an example," in Proc. the 2019 4th International Conference on Social Sciences and Economic Development (ICSSED 2019), Chen Dan, vol. 314, pp. 718-723, May 2019.

[12] T. Chen, L. Peng, B. Jing, C. Wu, J. Yang, and G. Cong, "The impact of the COVID-19 pandemic on user experience with online education platforms in China," Sustainability, vol. 12, no. 18, pp. 7329, Sept. 2020.

[13] X. Hu, S. Liu, Z. Xu, and G. Xiao, "Learning behavior analytics and learning effect evaluation for learners based on MOOCs," in Proc. 2016 International Conference on Educational Innovation through Technology (EITT), Tainan, 2016, pp. 1-5.

[14] D. Gamage, S. Fernando, and I. Perera, "Factors leading to an effective MOOC from participiants perspective," in Proc. 20158 th International Conference on Ubi-Media Computing (UMEDIA), Colombo, Sri Lanka, 2015, pp. 230-235.

[15] A. Kurnia, A. Lim, and B. Cheang, "Online judge," Computers \& Education, vol. 4, no. 36, pp. 299-315, May 2001.

Copyright $($ C 2021 by the authors. This is an open access article distributed under the Creative Commons Attribution License which permits unrestricted use, distribution, and reproduction in any medium, provided the original work is properly cited (CC BY 4.0).

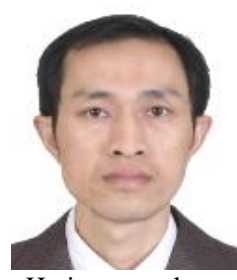

Dongqing Wu received the M.S. degree in computer graphics from the Institute of Industrial Design and Graphics, South China University of Technology, Guangzhou, China, in 2005, and the Ph.D. degree in mechanical engineering from the School of Electromechanical Engineering, Guangdong University of Technology, Guangzhou, China, in 2019.

$\mathrm{He}$ is currently a visiting scholar in the School of Computer Science and Engineering, Sun Yat-sen University, Guangzhou, China, and an associate professor with the School of Computational Science, Zhongkai University of Agriculture and Engineering, Guangzhou, China. His current research interests include neural networks, geometry algorithm, and pattern recognition.

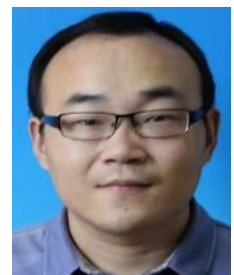

Pengfei Guo was born in Nov. 1988, Henan, China. He received the Ph.D. degree from the South China University of Technology, Guangzhou, China, in 2015. He is currently an associate professor with the School of Computing Science, Zhongkai University of Agriculture and Engineering, Guangzhou, China. His research interests include computer vision and image quality assessment.

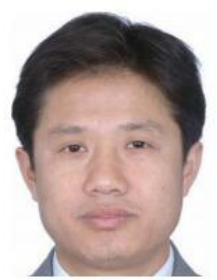

Chaolong Zhang was born in 1974. He has been a professor. He received the master's degree and $\mathrm{Ph} . \mathrm{D}$. degree in mathematics from South China Normal University, and South China University of Technology, Guangzhou,China. His main research interests include stability and control of stochastic systems, synchronization of network neural, stability and control of impulsive systems.

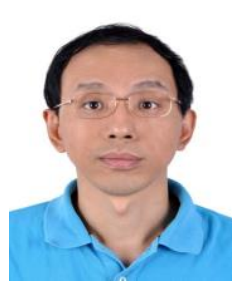

Chaojun Hou received his B. S. and M. S. degrees from South China University of Technology, Guangzhou, China, in 2001 and 2004, respectively. $\mathrm{He}$ received his $\mathrm{Ph} . \mathrm{D}$. degree in the Sun Yat-Sen University, Guangzhou, China, in 2009. His current research interests include agriculture engineering and artificial intelligence in agriculture.

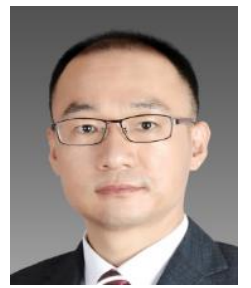

Wang Qian received the master's degree in software engineering from Sun Yat sen University in 2006 and is currently a lecturer in the school of computing science, Zhongkai University of Agriculture and Engineering, Guangzhou, China. His current research interests include neural networks, image processing and recognition.

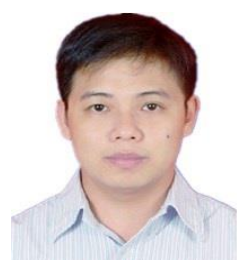

Zhiwei Yang received the B.Sc. degree in 2006, the M.Sc. degree in 2008 and Ph.D degree in 2018, all from Sun Yat-sen University, China. He is currently an associate professor at the college of computational science, Zhongkai University of Agriculture and Engineering, China. His research interests include vehicular ad-hoc networks and distributed systems, especially dynamic networks. He mainly focuses on information dissemination, counting, consensus and dynamic models in dynamic network, and has published related papers. 